\title{
Recurrent parotitis
}

Herman A Cohen, Samuel Gross, Moshe Nussinovitch, Moshe Frydman, Itzhak Varsano

\begin{abstract}
Recurrent parotitis in children is a well described but rare condition of unknown cause. The clinical features of 11 children with recurrent parotitis are described.
\end{abstract}

(Arch Dis Child 1992;67:1036-1037)

The aetiology and pathogenesis of chronic recurrent parotitis in children has of yet not been satisfactorily explained. It is characterised by a recurrent, painful swelling of the parotid gland, often with purulent sialorrhoea.

In most cases, sialectasis has been documented, sometimes in combination with ductal changes. ${ }^{12}$ The treatment should be conservative as the disease has a spontaneous recovery at puberty in most of the cases. ${ }^{3}$ We report a follow up of 11 cases of chronic recurrent parotitis.

\section{Patients and methods}

During the years 1984-9, 11 cases of chronic recurrent parotitis in children was followed up at the paediatric ambulatory, day care department at Hasharon Hospital. The diagnosis was based on clinical criteria and in five patients also on the radiological demonstration of sialectasis.

\section{Results}

The clinical features of the 11 children with recurrent parotitis are described in the table. Boys were affected more than girls. The age range was between $1 \cdot 2$ and 7 years. The mean exacerbation rate per year was 4.9 with a range of two to 12 attacks per year. The duration of the attack was two to five days. In most exacerbation attacks a mucopurulent discharge was pressed from the parotid gland. Bacterial culture revealed Streptococcus viridans and Haemophilus influenzae in most of the cases.

\footnotetext{
Department

Golda Medical Centre, Hasharon Hospital, Sackler School of Medicine, Tel Aviv University, Petach Tikvah, Petach

Herman A Cohen Samuel Gross Moshe Nussinovitch Moshe Frydman Itzhak Varsano

Correspondence to: Dr H A Cohen, Department of Paediatrics, Hasharon Hospital, 7 Keren-Kayemet Street, POB 121,

Petach Tikvah 49372 Israel.
}

Accepted 6 May 1992

Clinical features of 11 children with recurrent parotitis

Decrease in the exacerbation rate during follow up period

$+=$ Unilateral or bilateral parotitis present.
The symptoms were unilateral in six patients (right side $n=3$, left side $n=3$ ) and bilateral in five patients. All patients received antibiotics orally as the only treatment for exacerbations. Because of frequent recurrences of infection with abscess formation, patient 6 underwent total parotidectomy with good results. There were no underlying systemic diseases like Sjögren's syndrome, cystic fibrosis, rheumatoid arthritis, or systemic lupus erythematosus. Serological studies did not show a recent infection of mumps, Epstein-Barr virus, cytomegalovirus, or enteroviruses at the first presentation.

Eight out of 11 patients were completely free of clinical symptoms for at least 1.5-2 years. Two patients had a decrease in exacerbation rate. Patient 5 had three attacks during the last 12 months and patient 11 had one attack during the last 18 months of follow up. The patient who underwent partotidectomy has been completely free of symptoms for at least 2.5 years.

\section{Discussion}

Recurrent parotitis in children is a rare disease. The age of onset has been reported to range from 8 months to 16 years ${ }^{4}$ with the highest incidence between 3 to 6 years of age as documented in our patients. ${ }^{5}$ More boys than girls were affected. ${ }^{34}$ Different theories of aetiology and pathogenesis have been discussed over the years.

Bailey $^{7}$ and Smith $^{8}$ proposed a congenital abnormality as a predisposing factor. Familial background $^{169}$ and impaired rates of secretion was also reported. ${ }^{10}$ Immunological factors may also be involved. ${ }^{11} 12$

The affected children had multiple episodes of swelling of one or both parotid glands, sometimes in combination with pain and fever. Sialography reveals sialectasis in most cases with ductal changes in about one third of the

\begin{tabular}{|c|c|c|c|c|c|c|c|c|}
\hline $\begin{array}{l}\text { Patient } \\
\text { No }\end{array}$ & Sex & $\begin{array}{l}\text { Age of first } \\
\text { presentation } \\
\text { (years) }\end{array}$ & $\begin{array}{l}\text { No of } \\
\text { recurrences/year }\end{array}$ & $\begin{array}{l}\text { Duration } \\
\text { of symptoms } \\
\text { (years) }\end{array}$ & $\begin{array}{l}\text { Unilateral } \\
\text { parotitis }\end{array}$ & $\begin{array}{l}\text { Bilateral } \\
\text { parotitis }\end{array}$ & $\begin{array}{l}\text { Follow up } \\
\text { period } \\
\text { (vears) }\end{array}$ & $\begin{array}{l}\text { No of years } \\
\text { symptom free }\end{array}$ \\
\hline $\begin{array}{r}1 \\
2 \\
3 \\
4 \\
5 \\
6 \\
7 \\
8 \\
9 \\
10 \\
11\end{array}$ & $\begin{array}{l}M \\
\mathbf{F} \\
F \\
F \\
M \\
M \\
F \\
M \\
M \\
M \\
M\end{array}$ & $\begin{array}{l}2 \\
5 \\
6 \\
7 \\
1 \cdot 2 \\
6 \\
4 \\
5 \\
5 \cdot 5 \\
6 \\
3\end{array}$ & $\begin{array}{r}5 \\
4 \\
4 \\
2 \\
12 \\
6 \\
4 \\
5 \\
4 \\
5 \\
3\end{array}$ & $\begin{array}{l}3 \\
4 \\
2 \cdot 5 \\
3 \cdot 5 \\
3 \\
2 \\
3 \\
2 \\
4 \\
3 \\
5\end{array}$ & $\begin{array}{l}+ \\
+ \\
+\end{array}$ & $\begin{array}{l}+ \\
+ \\
+\end{array}$ & $\begin{array}{l}5 \cdot 5 \\
5 \\
4 \cdot 5 \\
5 \\
3 \cdot 5 \\
4 \cdot 5 \\
4 \cdot 5 \\
4 \\
5 \\
4 \cdot 5 \\
5\end{array}$ & $\begin{array}{l}3 \\
1 \cdot 5 \\
2 \\
2 \cdot 5 \\
\text { Decrease } \\
2 \cdot 5 \\
1 \cdot 5 \\
2 \\
2 \\
1 \cdot 5 \\
\text { Decrease }\end{array}$ \\
\hline
\end{tabular}


cases. The sialectatic changes are often found bilaterally, even if symptoms are unilateral. Normal sialograms have also been reported in symptomatic recurrent parotitis. ${ }^{1314}$

No correlation between the extent of the sialographic changes and clinical findings can be found. ${ }^{13}$ In most cases, the disease ends at puberty with a recurrence rate after puberty in $10-20 \%$ of the cases. Virgilio et al proposed the evidence of a clear distinction by clinical and development features between the infantile and adult form of chronic parotitis. ${ }^{14}$ Mucopurulent saliva may be pressed from the parotid duct and it can be a sign of persistent low grade infection. In most attacks, in the patients included in our follow up, bacterial culture of the mucopurulent discharge revealed $S$ viridans and $H$ influenzae.

All patients received oral antibiotics as the only treatment for exacerbation. Eight of the 11 patients were completely free of clinical symptoms for at least $1 \cdot 5-2$ years. Two patients had a decrease in the exacerbation rate during the follow up period. The patient who had total parotidectomy was completely free of symptoms for $2 \cdot 5$ years. Because of the tendency of spontaneous recovery of the disease before late puberty, conservative treatment and follow up are recommended in most cases.

Surgical treatment, for example ligature of Stensen's duct, ${ }^{10}{ }^{15}$ parotid parasympathectomy and parotidectomy ${ }^{16}$ are only recommended in the more severe cases. If parotidectomy is indicated then total parotidectomy is necessary with the associated substantial risk of postoperative facial weakness. The risk of permanent sequelae is small. ${ }^{16}$

1 Jones HE. Recurrent parotitis in children. Arch Dis Child 1953;28:182-6.

2 Vom Domath K, Gumdlach KKH. Eim beitragzur atiologie und pathogenese der chronisch-rezidivierenden parotitis.

3 Hemenway WG. Chronic punctate parotitis. Laryngoscope $1971 \cdot 81 \cdot 485-509$.

4 Kaban LB, Mullikem JB, Murray JE. Sialadenitis in childhood. Am f Surg 1978;135:570-6.

5 Brook AH. Recurrent parotitis in childhood. Br 7 Dermatol 1969;127:271-5.

6 Katzem M. Recurrent parotitis in children. S Afr $\mathcal{J}$ Surg 1969;7:37-42.

7 Bailey H. Congenital parotid sialectasis. Fournal of the International College of Surgery 1945;8:109-12.

8 Smith M. Familial incidence of sialectasis. BMF 1953;ii: 1359.

9 Galili D, Marmary Y. Juvenile recurrent parotitis clinicoradiologic follow-up study and the beneficial effect of sialography. Oral Surg Oral Med Oral Pathol 1986;61:550-6.

10 Maynard JD. Recurrent parotid enlargement. Br $\mathcal{f}$ Surg 1965;52:784-9.

11 Friis B, Karup Pedersen F, Schmidt M, Wiik A, Hoj L, Andersen V. Immunological studies in two children with recurrent parotitis. Acta Paediatr Scand 1983;72:265-8.

12 Konnoa A, Ito E. A study on the pathogenesis of recurrent parotitis in childhood. Ann Otol Rhinol Laryngol 1979;88 parotitis in

13 Geterud A, Lindvall AM, Nylem O. Follow-up study of recurrent parotitis in children. Ann Otol Rhinol Laryngol recurrent parotitis

14 Virgilio P, Bianchi PM, Bottero S, Pasquale M. The pathogenesis of chronic recurrent parotitis in infants: a study of 93 cases including an analysis of the vascular and glandular changes before and after parasympathectomy. Clin Otolarygol 1988;13:97-105.

15 Diamant $\mathrm{H}$. Ligation of the parotid duct in chronic recurrent parotitis. Acta Otolaryngol (Stockh) 1958;49:375-80.

16 Ariga MA, Myers EM. The surgical management of chronic parotitis. Laryngoscope 1990;100:1270-5. 